\title{
A COMUNICAÇÃO CORPORAL NO JOGO DE GOALBALL
}

THE BODILY COMMUNICATION IN THE GAME GOALBALL

\author{
LA COMUNICACIÓN CORPORAL EL JUEGO DE GOALBALL
}

\section{Pierre Normando Gomes-da-Silva*, Júlia Elisa Albuquerque de Almeida**, Djavan Antério*}

\section{Palavras-chave}

Linguagem.

Goalball.

Pessoas com deficiência visual.

Keywords

Language.

Goalball.

Visually impaired

persons.

\section{Palabras clave}

Lenguaje.

Goalball.

Personas con daño visual.
Resumo: Esta pesquisa objetivou analisar a comunicação corporal da pessoa com deficiência visual, atleta no jogo de goalball. Caracteriza-se como descritiva, de abordagem qualitativa e análise semiológica barthesiana. A amostra foi constituída por 22 atletas, categoria masculina, registrando e analisando o jogo final do Campeonato Norte-Nordeste de Goalball. Os resultados descreveram os significantes das jogadas, no Plano Expressão, evidenciando a riqueza perceptivo-motora. E, no Plano Conteúdo, os múltiplos significados cognitivos, emocionais e socioculturais do movimentar-se dos jogadores. Concluiu-se que o goalball é um jogo educativo porque, além da complexidade coordenativa e comunicativa, possibilita aos jogadores expandirem a atenção pelo corpo inteiro.

Abstract: The present study analyzed body communication of visually impaired goalball athletes. It is a descriptive, qualitative and Barthesian-semiological study. The sample consisted of 22 male athletes. The final match of Brazil's North-Northeast Championship of Goalball was recorded and analyzed. Results describe signifiers of the game's moves at Expression Level, showing motion-perceptive wealth; at the Content Level, it describes multiple cognitive, emotional and sociocultural meanings of players' movements. Goalball is found to be an educational game because, besides its coordination communication complexity, it allows players to expand their attention to their whole bodies.

Resumen: Este estudio objetivó analizar la comunicación corporal de la persona con discapacidad visual, atleta en el juego de Goalball. Es caracterizado como descriptivo, de enfoque cualitativo y análisis semiológico barthesiano. La muestra estuvo conformada por 22 atletas, categoría masculina, registrando y analizando el juego final del Campeonato Norte-Nordeste de Goalball. Los resultados describieron los significantes de las jugadas, en el Plano Expresión, evidenciando la riqueza perceptivo motora. Y, en el Plano Contenido, los múltiples significados cognitivos, emocionales y socioculturales de los movimientos de los jugadores. Se concluyó que el Goalball es un juego educativo, porque además de su complejidad coordinativa y comunicativa permite al jugador expandir su atención a todo el cuerpo.
*Universidade Federal da Paraíba, João Pessoa, PB, Brasil. E-mail: pierrenormandogomesdasilva@ gmail.com

** Prefeitura Municipal de João Pessoa. João Pessoa, PB, Brasil. E-mail: juliaelisa@ hotmail.com

Recebido em: 31-10-2013 Aprovado em: 13-01-2015

(c) (1) (8) Licence 


\section{INTRODUÇÃO}

Segundo os estudos de Çolak et al. (2004) e Amorim et al. (2010), o goalball foi criado em 1946 pelo austríaco Hans Lorenzen e pelo alemão Sett Reindle. O goalball foi pensado no sentido de contribuir na reabilitação dos veteranos de guerra cegos. Esse esporte foi apresentado ao mundo nas Paralimpíadas de 1976, em Toronto (Canadá), e os primeiros campeonatos mundiais se celebraram na Áustria, em 1978. Desde então, a sua popularização vem aumentando: até o momento, é jogado em 112 países e em todas as regiões que pertencem à International Blind Sport Federation (IBSA).

No Brasil, o goalball iniciou-se com o Clube de Apoio ao Deficiente Visual (CADEVI), na cidade de São Paulo, através do professor Steven Dubner. O primeiro Campeonato Brasileiro foi disputado em 1987, na cidade de Uberlândia-MG, e desde então vem sendo realizado anualmente, assim como os Campeonatos Regionais, com o intuito de elevar o nível técnico do esporte em nosso país. É um esporte coletivo pouco investigado, mas em crescente desenvolvimento paralímpico em vários países (AMORIM et al., 2010).

O esporte consiste em duas equipes de três jogadores cada, com o máximo de três substitutos por equipe. Sua quadra é retangular (18 $\mathrm{m}$ de largura por $9 \mathrm{~m}$ de comprimento), dividida em duas metades por uma linha central, com um gol em cada extremo (9 $\mathrm{m}$ de largura por 1,30 m de altura). É utilizada uma bola com guizos. A bola é arremessada com uma ou duas mãos (imitando um arremesso de boliche), com o objetivo que ela cruze rodando a linha do gol contrário. A outra equipe tenta impedir o gol, estando seus jogadores agachados ou ajoelhados. Através de deslocamentos laterais, buscam ocupar a maior área possível, deitando de lado na quadra para efetuar a defesa. Ganha o jogo a equipe que marcar a maior quantidade de gols em dois tempos de 10 minutos. As regras para a competição internacional de goalball são as adotadas pelo Comitê Paralímpico Brasileiro (2013).

No entanto, podemos relacioná-lo como conteúdo na Educação Física escolar, para alunos com deficiência visual ou não, uma vez que, segundo Libâneo (2001), o esporte apresenta uma capacidade educativa nas dimensões física, cognitiva, afetiva, social, ética, estética e ambiental. Vimos nessa pesquisa que o goalball abrange todas essas dimensões da personalidade humana. Para Libâneo (2001, p. 1) "[...] a Dimensão Física integra tudo o que diz respeito à motricidade humana, ao domínio do espaço, aos gestos e expressões do corpo". Para jogar goalball é necessário o desempenho de força e coordenação para os lançamentos; resistência anaeróbia devido aos deslocamentos curtos e rápidos; flexibilidade para fluidez nos movimentos (AMORIM et al., 2010). Além das habilidades motoras: arremesso e recepção, corrida e agachamento, giro e equilíbrio (MORATO et al., 2011; ÇOLAK et al., 2004). A Dimensão Ambiental dessa prática esportiva acontece na medida em que se solicitam as percepções de espaço, tempo e sensibilização aguçada dos sentidos remanescentes (audição e tato). É necessário incorporar os significados sobre os elementos constituintes do meio ambiente, visto que todo sistema de ação repousa na orientação espacial, como confirmam os estudos de Mauerberg-deCastro (2004).

A Dimensão Cognitiva é solicitada devido à necessidade de manutenção da concentração, construção de mapas espaciais internos e uso de pistas para orientação, além do que, todo movimento no goalball é aprendido pela mediação simbólica da verbalização (AMORIM et al., 2010). Esse conhecimento está ligado originariamente à nossa Dimensão Estética, porque 
nosso corpo é a instância primordial do sensível. É a ação do corpo se situando no mundo por meio do movimento perceptivo-motor nossa condição ontológica, daí a tese de que todo movimento é comunicativo (GOMES-DA-SILVA, 2012).

Destacamos a Dimensão Social e Ética, porque a prática desse esporte, além de produzir uma socialização, por ser um jogo de cooperação e oposição, e estar regulamentado por um código de regras internacionais, também conduz ao confronto do contexto sociocultural discriminatório, ao refletir como a diversidade é patrimônio cultural.

A Dimensão Emocional do goalball, a capacidade do autocontrole, está perpassada em todas as outras. Porque, no entender de Maturana (2002, p. 170), "[...] emoções são disposições corporais que especificam a cada instante o domínio de ações em que se encontra um animal (humano ou não), e que o emocionar, como o fluir de uma emoção a outra, é o fluir de um domínio de ações a outro". De modo que motor, cognitivo, estético, moral e social são ações coordenadas pela emoção.

Esse entrelaçamento congruente vivido no ambiente de convivência no jogo de goalball, denominamos de "zona de corporeidade" porque se constitui numa prática de linguagem (GOMES-DA-SILVA, 2011). Uma zona de comunicação em que ocorrem as coordenadas técnico-táticas dos jogadores, as interações recíprocas entre jogadores, adversários e ambiente e as sequências de condutas encadeadas. Maturana (2002, p. 152) denomina esse instante consensual do emocionar de "conversação"; e esta, antes mesmo da noção semântica, se constitui no processo biológico básico da linguagem.

Dessa forma, quando os professores de Educação Física estão trabalhando com o goalball, ou outra prática corporal, mais do que o desenvolvimento isolado de habilidades motoras, treinamento perceptivo e compreensão sociocultural, se está trabalhando linguagem, que integra todos esses elementos , porque se constitui na "zona de corporeidade" do jogo. De modo que a prática esportiva é um espaço de coordenadas de ação, portanto, de experiência de linguagem.

A linguagem é quando acontece um fluir de coordenações de conduta, tal como a comunicação corporal, que é um entrelaçamento congruente das correlações senso-motoras dos participantes, operando num espaço de coordenações consensuais. Linguagem como entrelaçamento de correlações é compatível com o entendimento da semiologia barthesiana, a partir da qual estruturamos nossa análise do goalball. Barthes (1992, p. 17) compreende linguagem como unidade heteróclita que liga termos díspares, não podendo isolar, "Já que participa, ao mesmo tempo, do físico, do fisiológico e do psíquico, do individual e do social". Também conceitua linguagem como "[...] toda síntese significativa, quer seja verbal ou visual: uma fotografia será, por nós, considerada fala exatamente como um artigo de jornal; os próprios objetos poderão transformar-se em fala se significarem alguma coisa" (BARTHES, 1987, p.133).

Linguagem é correlação de termos ou unidade sígnica. O signo está relacionado ao significar; portanto, é projeto de significação, informação, mediação e interação. Os signos interconectam estados do mundo, portanto são entidades dinâmicas, desenvolvem-se num processo contínuo de articular língua (instituição social, sistema abstrato, convencional) e fala (ato contextual, individual, de seleção e atualização). A ciência que estuda a atividade dos signos denomina-se Semiótica. A partir do final do século XIX, duas tradições científicas foram sistematizadas: semiótica americana (Charles S. Peirce, EUA, 1857-1914) e semiologia europeia (Ferdinand de Saussure, Suíça, 1857 - 1913). 
A tradição europeia desenvolveu vertentes distintas na França, com Roland Barthes, na Itália, com Umberto Eco, e na Rússia, com luri Lotman, para destacar os nomes mais notórios. A transposição da Semiótica para o campo da Educação Física é recente, mas tem rendido trabalhos profícuos em termos de pesquisas das práticas corporais e a intervenção docente como linguagem (BETTI; GOMES-DA-SILVA; GOMES-DA-SILVA, 2013). Por exemplo, tomar a comunicação corporal como saber docente, habilidade para mediar a situação educativa, seja compreendendo a atividade sígnica para melhor intervir em sala, seja treinando coordenações de ações dos jogadores (ANTÉRIO; GOMES-DA-SILVA, 2013).

Nesta investigação, optamos pela semiologia francesa, especificamente o (pós)estruturalismo de Roland Barthes (1915-1980), porque este mantém a paixão da linguagem não assertiva, mantém atitude crítica em relação à sociedade capitalista e se junta ao não fechamento na interpretação dos signos. Barthes (1988, p. 27) sustenta uma semiologia como "[...] série de operações ao longo da qual é possível fazer ondular o signo como um véu matizado, ou ainda, como uma ficção". Ele assim mantém um método dubitativo da escritura, como ressignificação contínua, próximo da literatura, da experiência corporal, do desejo do Neutro, do incerto, da consciência afetiva do vivido. Daí porque a linguagem, para Barthes, é tanto uma prática social presente nas narrativas visuais (fotografia, cinema, revista etc.) quanto é escritura, fruição, presente nas insinuações corporais (lutas, rostos, gestos, roupas, poesia, romances etc.). A semiologia, portanto, é uma linguagem sobre as linguagens, um modo de refletir sobre os signos, descobrindo as relações de exterioridade entre uma e outra linguagem.

Nesta perspectiva, analisaremos o jogo do goalball, atentos ao mundo dos signos, das coordenadas de ações à ambiência do silêncio, da benevolência, das provocações e das respostas vigorosas. O objetivo é fazer "escritura" da forma comunicativa desse impressionante jogo, produtor de uma linguagem de marcas: sem visão, mantêm-se as rotas e tarefas motoras em quadra, por meio das marcas da quadra e da direção do sonido da bola. Interessa-nos a situação do jogo, em seus processos de significação dos gestos dos jogadores em comunicação com companheiros, adversários e ambiente (bola, quadra, árbitros, torcida). Enfim, consideramos esses gestos como significantes, que remetem a significados internos e socioculturais implicados no jogo. Ou simplesmente diríamos que a movimentação dos jogadores será descrita como um texto, uma trama de elementos que expressam certo conteúdo, criando assim efeitos de significação.

\section{MATERIAL E MÉTODOS}

O presente estudo caracteriza-se como uma pesquisa descritiva, porque envolve análise de observações diretas e intensivas em ambiente natural, de abordagem qualitativa, porque buscou "[...] compreender o significado para os participantes da experiência e de que maneira os componentes combinam-se para formar um todo" (THOMAS; NELSON, 2002, p. 323). Contou com a colaboração de todos os participantes do Campeonato Regional Norte-Nordeste de Goalball, realizado em João Pessoa-PB.

A população deste estudo foi composta pelas quatro equipes masculinas e femininas. A amostra foi constituída pela categoria masculina, com 22 jogadores, correspondendo a $100 \%$ dos atletas e pela observação dos seis jogos do campeonato. A delimitação da amostra foi intencional, usando-se a seleção proposital de sujeitos. 
Os instrumentos e procedimentos usados para a coleta de dados foram: (1) Capacitação - durante um ano, adquirimos conhecimentos sobre as regras, participando de curso de arbitragem e formação técnica e tática da modalidade; (2) Estudo Piloto - três meses antes do início do campeonato foi realizado um estudo piloto para melhor aperfeiçoamento na pesquisa; (3) Consentimento dos participantes - no congresso técnico pactuamos com árbitros, técnicos e atletas sobre a autorização do estudo, conforme a autorização concedida pelo diretor da competição e o vice-presidente da CBDC - Confederação Brasileira de Desportos para Cegos, mediante assinatura do termo de consentimento (TCLE); (4) Entrevista - no alojamento dos atletas, após o primeiro dia de competição, cada equipe, individualmente, concedia informações referentes ao roteiro de questões, com o objetivo de caracterizá-los, quanto: a) Equipes: ADEVIRN - Associação de Deficientes Visuais do Rio Grande do Norte; APACE - Associação Paraibana de Cegos; APEC - Associação Pernambucana de Cegos e APADEVI - Associação Paraibana de Deficientes Visuais; b) sexo: $100 \%$ masculino; c) idade: 28,59 anos; d) estado civil: solteiro (82\%) e casados (18\%); e) grau de instrução: Ensino Fundamental incompleto (18\%); Fundamental completo (9\%); Médio incompleto (32\%); Médio completo (23\%); Superior incompleto (14\%) e Superior completo (5\%); f) classificação do grau de perda da visão, segundo IBSA: B1 (cego total- 68\%); B2 (baixa visão, com uma acuidade visual de até 2/60 - 27\%) e B3 (baixa visão, com uma acuidade visual de até $6 / 60-5 \%) ; g$ ) tempo de prática na modalidade: 3,45 anos; $h$ ) tempo de treino: dias/semana $(3,77)$ e horas/dias $(1,88) ;$ i) participação em campeonatos: Nordestinos (3,37); Brasileiros $(1,52)$; Parapan-americanos $(0,25)$ e Mundiais $(0,27)$.

(5) Observação direta - para a interpretação das jogadas fizemos o registro das observações destacando uma jogada, a mais proeminente (repetida) de todas, para ser analisada no jogo final; (6) Filmagem - o jogo final foi filmado por um profissional com câmara VHS, Panasonic M9000. Primeiro tempo gravado em ângulo sagital e nível alto e, no segundo tempo, em ângulo frontal e nível médio; (7) Edição das Imagens - editamos as imagens do jogo em DVD e selecionamos a jogada proeminente.

Para análise dos dados, o jogo foi estudado como um sistema semiológico, portanto, operando transações entre a face material e a face mental da jogada, ou ainda, como o gesto motor e expressão fisionômica estão acrescidos da apropriação social. A aventura semiológica de Barthes foi imensa, sua Oeuvres Complètes tem 5.500 páginas (MOTA, 2011). Em sua semiologia há pelo menos três metodologias, que o próprio autor identifica (BARTHES, 2001, p. 6-18): a primeira fase - política ou semioclastia, "método fundamental da crítica ideológica" (Mitologias, 1957/1987); a segunda fase - científica, "atividade de classificação", sistemática estruturalista (Elementos de semiologia, 1965/1992). Por fim, a terceira fase, estética ou fruição pós-estrutural, voltada mais para o "prazer no significante do Texto da Vida" (Lição, 1978/1988).

Aqui resolvemos adotar o segundo modelo barthesiano (BARTHES, 1992), aquele de uma semiologia mais relacionada com a ciência, portadora de um protocolo operatório a partir do qual se analisam as narrativas. Um método, mesmo que não heurístico, não para decifrar ou subjugar o signo, mas para descrever os significantes em dois planos (Expressão e Conteúdo) com seus dois estratos (Forma e Substância). Utilizamos, portanto, as quatro classes para descrever o caráter comunicativo do goalball: Forma e Substância da Expressão \& Substância e Forma do Conteúdo.

A manifestação sensível do jogo, isto é, o que podemos captar por meio da percepção, que são os significantes, recebe o nome de Plano de Expressão do jogo. E os significados, 
que se relacionam com o sentido ou a representação psíquica produzida pelas jogadas, que são unidades significativas, recebem o nome de Plano de Conteúdo do jogo. Esses planos são descritos por dois elementos: Forma e Substância. A Forma é o que pode ser descrito exaustiva, simples e coerentemente da observação do jogo, sem recorrer a outra premissa, e a Substância se refere aos aspectos do jogo, ao caráter aglutinador da cadeia das jogadas. Se não fosse esse poder de coesão da Substância, a cadeia de movimentos seria um ajuntamento incompreensível. Evidente que é a junção dos dois Planos que nos dá a significação do jogo. A subdivisão "Forma/Substância" foi por nós utilizada, de modo original, para compreensão do esporte, porque nos ajudou a manejar com toda a produção sígnica dada na comunicação corporal do goalball.

\section{RESULTADOS E DISCUSSÃO}

Neste ponto, analisamos o potencial educativo do jogo de goalball a partir do processo de significação dado nos planos e extratos semiológicos da jogada do pênalti (High ball), do jogo final do campeonato, entre as equipes da APACE e da ADEVIRN, o qual terminou empatado com o placar de $7 \times 7$.

\subsection{Plano expressivo do Goalball}

Para análise do goalball como sistema semiológico, especificamente a jogada do pênalti, captamos sua estruturação no Plano Expressivo, em suas duas classes. A Substância da Expressão (conjunto de unidades significantes mínimas) manifesta a Forma da Expressão (agrupa essas unidades em relações sintagmáticas e paradigmáticas - encadeamento extensivo de ações e associação mental da unidade).

\subsubsection{Substância da Expressão do Jogo}

0 placar está $0 \times 0$. As equipes estão com os olhos recobertos por bandagens e vendados, uniformizadas, com camisa numerada, calça, cotoveleiras, joelheiras, coquilha e tênis. A equipe da APACE, nesse instante, é a defensora. Os três defensores ocupam suas respectivas posições: ala direita, pivô e ala esquerda, utilizando o tato das mãos para achar as linhas de orientação de alto relevo.

O ala esquerda e o pivô semelhantemente executam a "expectativa alta": cabeça erguida; tronco inclinado à frente; membros superiores com extensão total dos cotovelos, antebraços supinados e apoiados sobre as coxas. Posição de agachamento, membros inferiores fletidos, pernas afastadas lateralmente à largura dos ombros, com as solas dos pés apoiadas no solo. $O$ ala direita, em "expectativa baixa": cabeça flexionada lateralmente com ouvido dominante, voltado para o lado direito; tronco inclinado à frente, paralelo ao solo; flexão dos cotovelos, abdução dos ombros, antebraços pronados com extensão dos punhos, palmas das mãos tocando o solo; extensão total do joelho e abdução da coxa, com a sola do pé apoiada no solo.

Após a bola ter sido arremessada pela equipe da ADEVIRN, a equipe da APACE defenderá seu gol. Através do sentido da audição os defensores orientam-se para identificar a trajetória da bola arremessada e, assim, reagir rapidamente defendendo-a. 
Os jogadores em sincronia posicionam-se, defendendo em diagonal. O som da bola passada pela equipe adversária serve como pista de orientação. Os alas se posicionam na sua própria linha e deslizam lateralmente pela quadra tentando fechar o gol. $\mathrm{O}$ ala direita cobre a linha lateral, deitando-se e fixando os braços para dentro da quadra. 0 pivô defende mais ao centro, deixando as sobras de espaços para o ala esquerda, que defenderá a partir do centro. Os jogadores, na fase final do movimento, defendem em decúbito lateral; tronco ereto, abdômen contraído; braços estendidos acima da cabeça, com os antebraços pronados; a cabeça voltada para trás dos braços; as pernas estendidas sendo que a de cima levemente abduzida e ligeiramente à frente da perna inferior; e o pé em eversão.

Um erro na orientação espacial foi observado pelo árbitro principal posicionado à frente da linha demarcatória da área de ataque. Este está semiajoelhado, com o olhar atento e voltado ao local em que a bola toca o solo pela primeira vez, após sair da mão do atleta arremessador. $O$ ala esquerda da ADEVIRN arremessou a bola além dos limites da área permitida, cometendo uma penalidade, marcada por meio de um silvo de apito e da verbalização do árbitro principal, "high ball" (bola alta), então o jogo é paralisado.

Com a marcação da penalidade, pênalti, o ala esquerda, único responsável por essa defesa, desloca-se, toca na trave e posiciona-se. O jogo seria reiniciado pelo juiz de linha através da reposição de bola para a equipe da APACE. Entretanto, antes que isto ocorresse, o próprio jogador da ala esquerda foi de encontro à bola, recuperando-a para ser entregue ao máximo silêncio para o atleta cobrador da penalidade.

Os jogadores da APACE aproveitam essa situação para fazer trocas de posição. O pivô e 0 ala direita posicionaram-se em pé, à esquerda da área de defesa. 0 cobrador da penalidade, 0 ala direita, manifesta-se para receber a bola, volta ao meio de quadra tateando o travessão superior, quando ao ser tocado pelo ala esquerda faz um gesto de supinação dos antebraços, pedindo a bola ao seu parceiro. $\mathrm{O}$ ala direita desloca-se até a extremidade direita e, com um gesto de braço direito estendido, antebraço pronado e elevado acima da cabeça, com os dedos mínimo, anular e polegar flexionados e voltados uns para os outros, com apenas os dedos indicador e médio estendidos e afastados lateralmente, executa uma circundução do punho.

O árbitro principal, após conferir as posições de cada equipe e o silêncio absoluto em quadra, autoriza a cobrança do pênalti através de um silvo de apito e do comando "play". O ala direita da APACE toca na trave e reconhece todo espaço para realizar o arremesso, sabe que terá $6 \mathrm{~m}$ à sua frente e $10 \mathrm{~s}$ para tentar $0 \mathrm{gol}$.

Técnica de lançamento: sai da ala direita, executando uma corrida preparatória em diagonal para o centro da área de defesa e, ao chegar aos últimos três metros do arremesso, realiza na área de lançamento três passos com giro de 360․: perna esquerda, direita e esquerda. No primeiro passo, a bola passa a ser segurada com apenas uma mão, no encaixe entre a flexão do punho e o antebraço. 0 braço dominante realiza a extensão completa do cotovelo, e através de um balanceio de trás para frente, reúne a força necessária na tentativa de marcar um gol. 0 tronco faz uma rotação do lado esquerdo para o direito, com grande inclinação para frente. $\mathrm{O}$ arremesso finaliza com a perna direita abduzida atrás da esquerda, estendida e com o pé em flexão plantar.

O ala esquerda da equipe da ADEVIRN posiciona-se na linha central da área de equipe, executando a posição de "expectativa baixa", orientando-se para realizar a marcação e 
realizar o "blocked" (bola defendida). Entretanto, a bola havia sido arremessada com tanta força que, mesmo batendo em suas coxas, não foi possível evitar o gol, porque ela assumiu uma nova trajetória (parábola), encobrindo o defensor, dificultando a interceptação decisiva, atingindo a rede no fundo da meta.

Neste momento os juízes de linha sinalizam o gol. É quando o árbitro principal do lado correspondente à equipe da ADEVIRN emite dois silvos de apito e verbaliza "gol". A torcida, que ouviu a marcação do gol, grita, agita-se e zomba da equipe adversária. Após alguns segundos, a torcida volta ao silêncio, o árbitro do lado da equipe da APACE ergue a cabeça com o olhar voltado para a mesa de arbitragem, conferindo o placar, então verbaliza "gol APACE, placar um a zero".

As fisionomias nos rostos dos atletas da APACE é a mesma: sorriso amplo; o pivô com grande alegria bate palmas, motivando a equipe a permanecer à frente do placar. Na equipe da ADEVIRN, a face é raivosa, sobrancelhas baixas, extremidades da boca voltadas para baixo e, no atleta defensor, além dessa expressão, fica sobreposta a posição ereta e tensa ao se levantar do chão, voltando-se lateralmente à equipe oponente, com os braços flexionados a $90^{\circ}$, encostados lateralmente ao tronco e os punhos cerrados.

\subsubsection{Forma da Expressão do Jogo}

Durante a própria descrição substancial da jogada a Forma já estava sendo delineada; impossível separá-la, sob pena de perder o sentido. Mas resolvemos aqui destacar os agrupamentos das unidades das relações interindividuais: venda nos olhos, uniforme esportivo, linhas da quadra-regras-arbitragem, posições de defesa, máxima concentração em busca da posse da bola, orientação tátil e auditiva, comunicação corporal entre companheiros, ataque com técnicas de lançamento, tomada de decisão, tempo de reação, comunicação de confronto aos adversários, torcidas, silêncios, penalidades, corrida-giro-arremesso, sorrisos e tensões.

\subsection{Plano do conteúdo do goalball}

Passemos agora à estruturação no Plano do Conteúdo, em suas duas classes. A Substância do Conteúdo (associações do significado) manifesta a Forma do Conteúdo (organização dos significados entre si).

\subsubsection{Substância do Conteúdo do Jogo}

Olhos recobertos, com bandagens e vendas como uso obrigatório. Os jogadores não podem nem tocar nas vendas durante o jogo sem autorização do árbitro. A finalidade é manter a condição de igualdade entre aqueles com graus diferentes de perda de visão. "A falta de visão tem um impacto grave na navegação em ambientes complexos e com rotas irregulares", dizem Mauerberg-DeCastro et al. (2004, p. 201). Ou, como afirmam Morato et al. (2011, p. 98), a visão "[...] é mediador de outras impressões sensoriais e age como estabilizador entre a pessoa e o mundo exterior". Mas o goalball insiste, o jogo é sem visão. Todos na escuridão, entregues à necessidade corporal de adaptação, de desenvolver estratégias compensatórias no sistema de orientação. 
As linhas em alto relevo, os silvos de apito e as palavras do árbitro e o som dos guizos na bola são os indícios para outro sistema de orientação desenvolver-se. Neste jogo, diferente de tantos outros esportes, a função visual está privada. A percepção tátil, mãos tateando linhas e balizas para orientar-se no jogo, é estratégia para defesa e ataque. E também o é a percepção auditiva, cabeça inclinada para o ouvido melhor avaliar distância, trajetória e velocidade da bola, que vem rolando no solo. Então, a imediata ação: deitando-se em diagonal à frente, fechando o gol. Nesse jogo, as exigentes tarefas de orientação espacial fazem com que os jogadores incorporem uma representação geométrica do espaço. É um jogo indicial, tátil-auditivo, a partir do qual desenvolvem a habilidade de coordenar a ação com direção no meio ambiente.

As relações corpo-mão e corpo-ouvido no goalball significam obtenção das informações espaciais. O canal cutâneo da mão é a fronteira entre o indivíduo (jogador de goalball) e 0 meio (espaço de jogo). E o canal auditivo é o responsável pela detecção da velocidade da bola e posição do lançador. Num sistema cutâneo-auditivo, os esforços de captação ativa do ambiente realizam uma estratégia de leitura do jogo, seja no ataque ou na defesa. Esse sistema de orientação interpreta a complexa rede de informações do ambiente do jogo e se escolhe a resposta coerente para a situação (MORATO et al., 2011).

O uniforme esportivo, com equipamento de segurança e proteção para cotovelos, joeIhos e órgãos genitais, denota um esporte de muito contato, não entre os oponentes, mas entre os jogadores e o chão. Daí as possibilidades reais de acidentes, inclusive há previsão da "regra de sangue" (IBSA, 2013), quando o jogo é paralisado pelo árbitro que identifica contusão com sangramento. É um jogo arriscado, que exige de quem joga uma bravura em lançar-se ao chão para defesas. A missão é de combate: impedir o gol com a manobra do corpo lançado ao chão.

Essa significação sociocultural é apoiada pelas Substâncias da Expressão (formato da quadra e funcionamento do jogo) e pelo objetivo e contexto da criação do jogo. 0 objetivo original era devolver a capacidade de concentração e qualidades físicas necessárias para a reabilitação dos soldados que ficaram cegos após a Segunda Guerra Mundial (ÇOLAK et al., 2004). O goalball não foi adaptado de nenhum outro esporte e no período de sua criação persistiam os ideais filosóficos de guerra, por isso é possível identificar alguns elementos ritualizados da guerra, seja no cuidado com as vestimentas de proteção, seja pela delimitação das áreas de jogo: neutra (não pode haver invasão), ataque (realização de arremessos) e defesa (proteção do gol). Seja pela bola arremessada com força, com a função projetil de sobrepujar o adversário. 0 goalball é mais um flagrante exemplo da aproximação imaginária entre jogo e o combate intensivo e enérgico, que anunciou Huizinga (1996).

Toda formação de jogo é iniciada na área de defesa, onde se exige máxima concentração e prontidão para ação. As equipes oponentes não se tocam, mas se enfrentam pela bola-projetil. Há alternância contínua entre os papéis de atacantes e defensores: após o arremessador atacar, ele imediatamente retorna para ocupar posição de defesa. E os que defendiam tornam-se agora atacantes, numa reversibilidade contínua de posse da bola. Os deslocamentos nas áreas implicam mudanças de funções: defesa e ataque.

As posições de defesa constituem a comunicação entre companheiros. Três jogadores devem criar uma barreira corporal cobrindo todo o gol. Inicialmente em expectativa, seja "alta" (pivô e ala esquerda) ou "baixa" (ala direita). Após o arremesso adversário na restrita área de ataque, os defensores realizam: discriminação auditiva, eficácia na tomada de decisão, rapidez na reação para interceptar a bola e unanimidade ao lançar-se ao chão. Numa unidade corporal, 
eles tornam a área de defesa um "espaço pessoal, no qual um intruso não pode penetrar" (CORRAZE, 1982, p. 122). Essa unidade, em que cada corpo realiza sua função, é demonstração de poder: a incapacidade dá lugar à potencialidade. A defesa em sua prontidão, percepção do sinal sonoro, leitura de jogo e tempo de reação para o deslize demonstram a eficiência dos jogadores para, em dez segundos, interceptar, dominar a bola e atacar com lançamento (SILVA et al., 2010).

As habilidades motoras de ataque constituem a ofensiva do arremesso, investido de força e de significação social. O silêncio nesse jogo é comunicação, tática de ataque. É utilizado para enganar a equipe adversária, omitindo o sonido da bola, para não denunciar sua posição e os adversários se protegerem. Silêncio é ocultar a informação para surpreender o adversário, atingindo-o num flanco que não estava prevenido. Essa arte de falsear ou ocultar a informação para comprometer a ação dos adversários é denominada de contra-comunicação, por Parlebas (2001). Foi nesse silêncio que ocorreu a cooperação do passe, recepção e lançamento da bola, com efeito, devido ao giro em torno de si mesma.

O árbitro é soberano, único que vê em quadra, representante da lei e aplicador das regras para manutenção das condições de igualdade entre as equipes. É o único capaz de comunicar-se diretamente com a torcida, solicitando silêncio ou paralisando o jogo. Com seus silvos de apito e verbalizações exerce a comunicação do imparcial.

Na comunicação da penalidade, o jogador retorna sozinho à sua trave, num sinal de prostração, gesto de abatimento moral, por sentir prejudicar sua equipe através de seus próprios atos. Para remir o erro cometido, ao deixar a bola ultrapassá-lo, concentra-se para evitar o gol, numa chance de recuperar a honra e anular a vantagem da equipe adversária.

A comunicação da torcida é cíclica, ora com gritos de euforia, ora com silêncios absolutos. No silêncio, aprecia a sequência das sucessivas jogadas como espetáculo. E ouve com atenção a narração pelos árbitros. 0 entusiasmo com o ataque é pela magnitude do lançamento: corrida de impulsão na diagonal, aquisição de propulsão ao modificar a velocidade, concentrando a energia cinética na troca de passadas; giro de 360, com rotação, inclinação do tronco; flexão de pulso, segurando a bola, balanceio do braço de arremesso estendido e finalização com os dedos indicador e médio dando direção e força precisas. 0 encanto da torcida está em perceber que "o cego não tem percepção visual, mas possui o olhar [...] enraizado na corporeidade através da sensibilidade e da motricidade", explica Bosi (apud SANTOS, 2001, p. 6). Após a declaração de gol pelos dois juízes de linha e árbitro principal a euforia toma conta da torcida. E, numa expressão de regozijo, se vangloria em face da torcida adversária, superada momentaneamente.

A expressão excessiva de felicidade é notória na face da equipe que vence: sorriso amplo e batida de palmas. Em oposição, na equipe que está perdendo a expressão é de decepção e tensão. Mas seus punhos cerrados, segundo Guiraud (1991, p. 34) são ícones de "profunda determinação e ameaça". Portanto, os passos seguintes na partida prometem ser tensos, já que agora a defesa torna-se ataque.

\subsubsection{Forma do Conteúdo do jogo}

Organizando a substância destes significados (sistema de orientação cutâneo-auditivo, atitude de combate e excessiva comunicação), chegamos à marca semântica desse jogo, a 
Forma do seu Conteúdo. Vimos que o jogo tem início tímido, pelo tatear das linhas, depois agudez de escuta dos sonidos e, por fim, o jogador realiza um bailado no arremesso. Essa sequência é a linguagem do jogo; numa comunicação com o entorno do jogo, o jogador recupera a graça de "ver" e aumenta sua motilidade, desde o contato com as linhas sobressalentes no piso até o movimento de fluxo livre com giro de $360^{\circ}$ com arremesso. A pesquisa de Çolak et al. (2014) comprova: crianças com diferentes graus de cegueira, de 13 a 15 anos, que praticam goalball apresentam uma melhora significativa, em termos de habilidades motoras, em relação às que não praticam.

No goalball o cego liga-se ao chão como possibilidade de embasamento, de consciência de realidade, de atenção defensiva, para uma fluência comunicativa do ataque. 0 goalball é um jogo horizontal, no qual o jogador projeta seu corpo para todos os espaços da quadra, por meio das posições de Expectativas e de vigorosos arremessos. Esse ambiente corporalizado do jogo, em que, ao nos movermos em interação com espaço e tempo, criando uma atmosfera existencial, denominamos de zona de corporeidade: "[...] comunicabilidade ontológica proveniente do impulso fundamental que move a vida rumo ao encontro e o homem rumo à troca de signos, operação fundante do ser". (GOMES-DA-SILVA, 2011, p. 126).

Pela semiologia barthesiana (BARTHES, 2001), fica evidente que no goalball essa zona de corporeidade é a semântica do contato. Uma linguagem evidenciada pelos movimentos em interação perceptivo-motora com o meio para defesas e ataques. A atmosfera criada pela movimentação no goalball é a da atenção horizontal, construída rente ao chão, ao contrário da verticalidade, tão valorizada por outros esportes.

Em LMA (Análise de Movimento de Laban) o fator de movimento espaço refere-se à atenção do indivíduo a seu ambiente ao mover-se, podendo estar centrada num ponto (foco direto) ou em diversos ao mesmo tempo (multifoco). Mesmo destacando a visão como a principal responsável pela atenção ao espaço, ou associando o foco aos olhos, a LMA refere-se ao corpo todo, visto que a atenção ao espaço implica uma atitude interna, um "olhar". No goalball a atenção ao espaço está expandida por milhares de pontos, "como se seu corpo tivesse olhos em todos os poros, e se movesse com todos esses simultâneos focos" (FERNANDES, 2002, p.108).

A zona de corporeidade no goalball favorece a compreensão do mundo por suas qualidades táteis e auditivas, formando uma consciência da espacialidade, pelas experiências dos movimentos. Essa experiência é de um corpo que "vê" através de seus sentidos remanescentes e aguçados, gerando uma nova atitude de interação pessoal e social. Portanto, na vivência do goalball pelos alas e pivôs, defendendo ou atacando, a expressividade é multifocal e vigorosa. Seja se lançando, deslizando pelo chão, ou fazendo giros, a comunicação estabelecida é na direção da "corporeidade poetante" (GOMES-DA-SILVA, 2011), aquela movimentação comunicativa criadora de uma atmosfera de atenção aberta às mudanças dos espaços exteriores e internos, integrativa das sensações corporais e das expressões emocionais, cognitivas e culturais. Portanto, nesse jogo há a aprendizagem do contato, cuja maneira de ser no mundo é da identificação com a própria experiência corporal, com integração emocional/cognitiva na ação e abertura perceptiva à comunhão com a realidade externa. 


\section{CONCLUSÕES}

Essa é a tarefa semiótica, operar classificando significados. E assim fizemos, quando os gestos, inicialmente de origem pragmática ou funcional do jogo, ganharam significações. As ações de uso, próprias do esporte, que, segundo Barthes (1992), poderíamos denominar "função-signo", passaram por um duplo movimento: primeiro a decomposição, classificando-a em sua função no jogo (Plano da Expressão), depois, pela funcionalização recorrente, penetrada de sentido, a semantização (Plano de Conteúdo). Ou seja, a função da penalidade e do arremesso ao gol ganhou uma segunda instância, a do signo.

Eis o signo: "ao jogar goalball, o cego parece ver". É na sua comunicação corporal com o meio que se abre um "olhar" pela sinestesia, pela expansão da atenção, acurácia na orientação dinâmica. Assim o jogador passa a compreender o mundo através da experiência do corpo em movimento. Esse jogo fornece uma reaprendizagem existencial, na medida em que parte do impedimento de ver e cria um espaço lúdico que possibilita o orientar-se por outros canais. A finalidade é tornar evidente ao professor de Educação Física a potencialidade educativa do goalball, para enriquecer suas aulas, seja para pessoas com deficiência visual ou não. Ainda mais, o intuito é aflorar um novo enfoque pedagógico, para que as situações de movimento sejam compreendidas como linguagem, em seus significados culturais, lógicos e motores, como afirmaram Soares, Gomes-da-Silva e Ribas (2012).

É importante que a prática do goalball - mesmo sendo um esporte de alto rendimento para Paralimpíadas, Jogos Mundiais, Parapan-americanos, Brasileiros e Regionais - seja estendida para pessoas com visão normal. Pois os alunos, ao vendarem seus olhos e participarem desse jogo, descobrem um novo modo de comunicar-se com o meio, ampliam sua capacidade perceptiva e vivenciam outra zona de corporeidade, dantes não possível. Porque começam a organizar seu foco de atenção para muitos pontos, percebendo todo o ambiente, despertando um "olhar" de corpo inteiro.

Essa exigência de atenção para as referências móveis e fixas desperta um estado de alerta, otimiza a função de orientação e a criação de mapas mentais. A prontidão de ação, rapidez na tomada de decisão e tempo de reação e competência dos gestos possibilitam um encontro consigo mesmo, na medida em que 0 aluno se percebe inteiramente envolvido com as áreas da quadra, o sonido da bola, o fechamento do gol, a unidade corporal com os companheiros, os silêncios táticos e os fortes arremessos sobrepujando os adversários.

\section{REFERÊNCIAS}

AMORIM, Minerva et al. Goalball: uma modalidade desportiva de competição. Revista Portuguesa de Ciências do Desporto, Porto, v. 10, n. 1, p. 221-229, 2010.

ANTÉRIO, Djavan; GOMES-DA-SILVA, Pierre Normando. Decodificando as ações corporais na prática docente. Conceitos, João Pessoa, v. 1, n. 18, p. 81-88, ago. 2013.

BARTHES, Roland. A aventura semiológica. SP: Martins Fontes, 2001.

BARTHES, Roland. Elementos de semiologia. 15. ed. São Paulo: Cultrix, 1992.

BARTHES, Roland. Lição. Lisboa: Edições 70, 1988.

BARTHES, Roland. Mitologias. 7. ed. São Paulo: Difel, 1987. 
BETTI, Mauro; GOMES-DA-SILVA, Pierre; GOMES-DA-SILVA, Eliane. Uma gota de suor e o universo da educação física: um olhar semiótico para as práticas corporais. Kinesis, Santa Maria, v. 31, n. 1, p. 91-106, jan.jun. 2013.

ÇOLAK, Tucay et al. Physical fitness levels of blind and visually impaired goalball team players.

Isokinetics and Exercise Science, Amsterdam, v. 12, n. 4, p. 247-252, 2004.

COMITÊ PARALÍMPICO BRASILEIRO. Regras goalball: IBSA, 2013. Disponível em: http://www. cpb.org.br/modalidades/goalball/. Acesso em: 14 jul. 2013.

CORRAZE, Jacques. As comunicações não-verbais. Rio de Janeiro: Zahar, 1982.

FERNANDES, Cine. 0 corpo em movimento. São Paulo: Annablume, 2002.

GOMES-DA-SILVA, Pierre Normando. A corporeidade do movimento. In: HERMIDA, J. F.; ZOBOLI, F. Corporeidade e educação. João Pessoa: Editora Universitária UFPB, 2012.

GOMES-DA-SILVA, Pierre Normando. A cultura do jogo e o jogo da cultura: por uma semiótica da corporeidade. João Pessoa: Editora Universitária UFPB, 2011.

GUIRAUD, Pierre. A linguagem do corpo. São Paulo: Ática, 1991.

HUIZINGA, Johan. Homo ludens: o jogo como elemento da cultura. 4. ed. São Paulo: Perspectiva, 1996.

IBSA. Comitê Paralímpico Brasileiro. Regras do Goalball: IBSA 2010-2013. Tradução: Natalia de Almeida Ordacgi Caldeira, 2013. Disponível em: http://goo.gl/HYl45O. Acesso em: 14 jul. 2013.

INTERNATIONAL BLIND SPORTS FEDERATION. [Site]. Disponível em: http://www.ibsasport. org/. Acesso em: 26 maio 2014.

LIBÂNEO, José Carlos. A dimensão pedagógica da educação física: questões didáticas e epistemológicas. In: CONGRESSO BRASILEIRO DE CIÊNCIAS DO ESPORTE, 12., 2001, Caxambu, MG. Anais... Caxambu, CBCE, 2001. v.1, p.1-9.

MATURANA, Humberto. A ontologia da realidade. Belo Horizonte: Editora UFMG, 2002.

MAUERBERG-DECASTRO, Eliane et al. Orientação espacial em adultos com deficiência visual: efeitos de um treinamento de navegação. Psicologia: Reflexão e Crítica, Porto Alegre, v. 17, n. 2, p.199-210, 2004.

MORATO, Marcio et al. A leitura de jogo no futebol para cegos. Movimento, Porto Alegre, v. 17, n. 3, p. 97-114, jul./set. 2011.

MOTTA, Leda T. Roland Barthes: uma biografia intelectual. São Paulo: lluminuras/ FAPESP, 2011.

PARLEBAS, Pierre. Juegos, deporte y sociedad: léxico de praxiología motriz. Barcelona: Paidotribo, 2001.

SANTOS, Admilson. O corpo cego. Revista Benjamin Constant, Rio de Janeiro, v. 7, n. 20, p. 3-6, dez. 2001.

SILVA, Gilberto Pereira et al. Tempo de reação e a eficiência do jogador de goalball na interceptação/ defesa do lançamento/ataque. Motricidade, Santa Maria da Feira, v. 6, n. 4, p. 13-22, 2010.

SOARES, Leys; GOMES-DA-SILVA, Pierre N.; RIBAS, João F. Comunicação motriz nos jogos populares: uma análise praxiológica. Movimento, Porto Alegre, v. 18, n. 3, p. 159-182, jul./set. 2012.

THOMAS, Jerry R.; NELSON, Jack K. Métodos de pesquisa em atividade física. 3. ed. Porto Alegre: Artmed, 2002. 


\section{ANEXO A: FIGURAS}

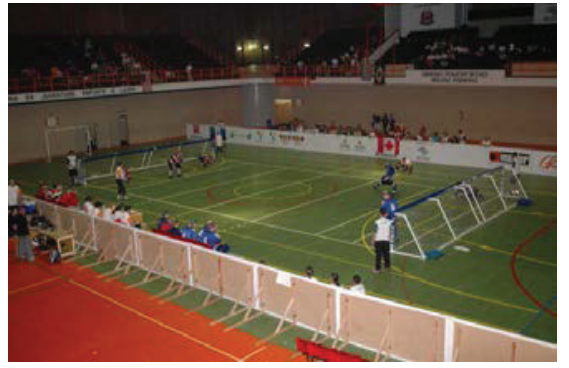

Figura 1 - Quadra de jogo: disposição das equipes, árbitros, juízes de linha, técnicos e atletas reservas

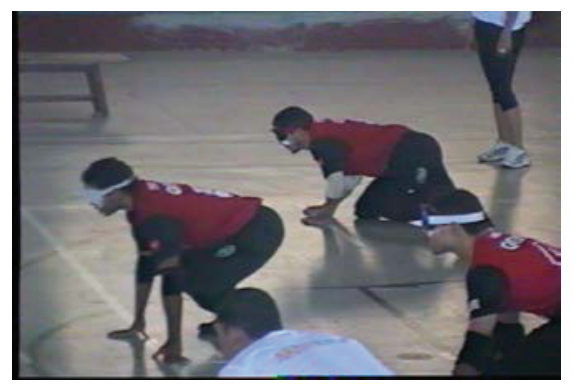

Figura 3 - Posição de expectativa da defesa

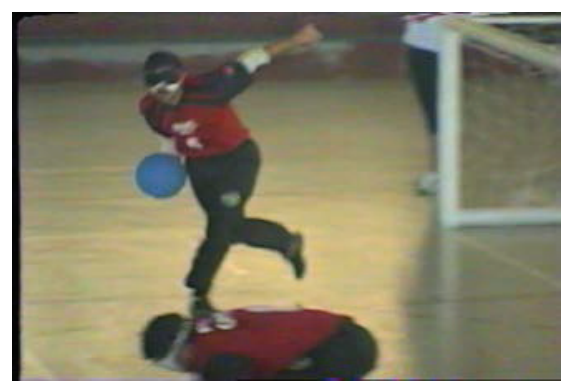

Figura 5 - 1ำ passo do arremesso com giro

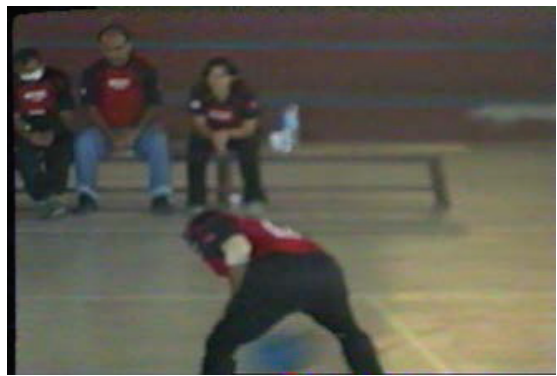

Figura 7 - 3ำ passo do arremesso com giro

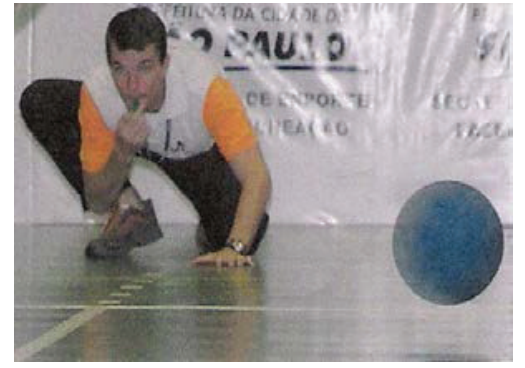

Figura 2 - Posição do árbitro

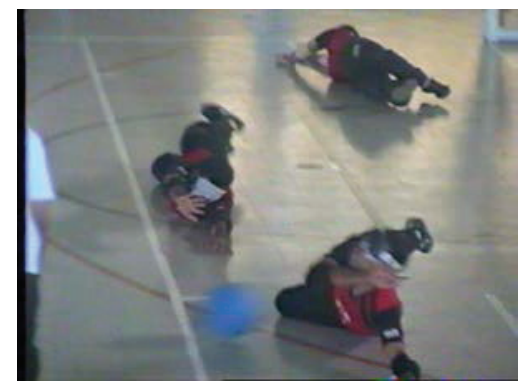

Figura 4 - Posição final de defesa

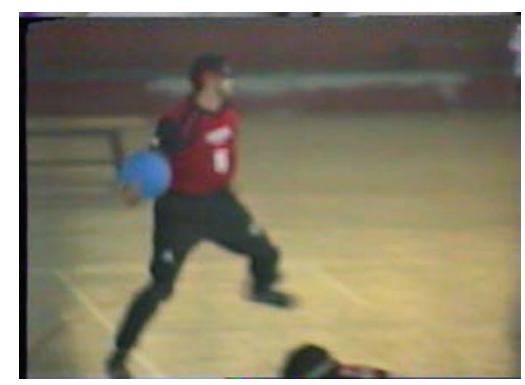

Figura 6 - $2^{\circ}$ passo do arremesso com giro

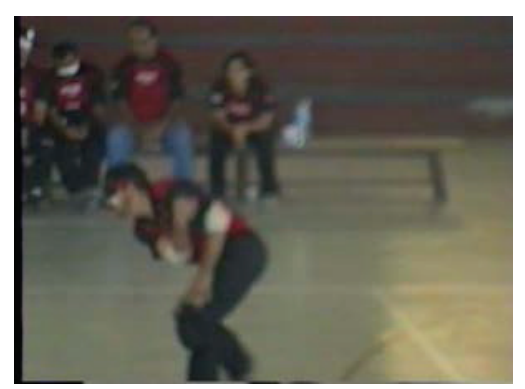

Figura 8 - Finalização do arremesso 


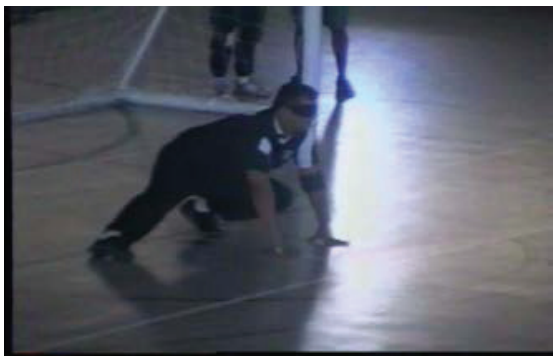

Figura 9 - Posição de defesa

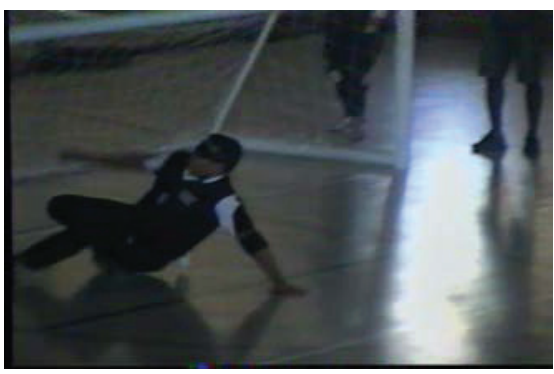

Figura 11 - Tentativa de interceptação após a bola assumir trajetória em parábola

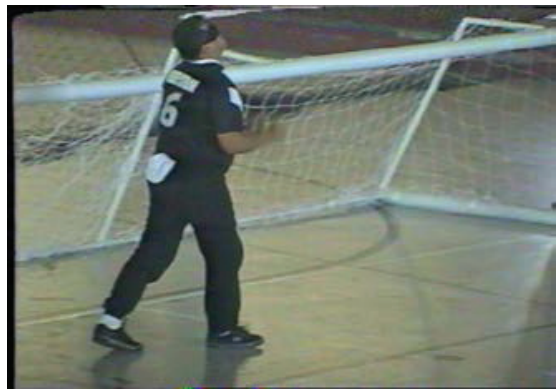

Figura 13 - Expressão de angústia

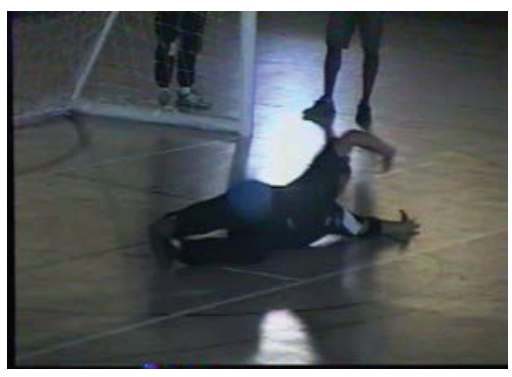

Figura 10 - Bloqueio parcial da bola

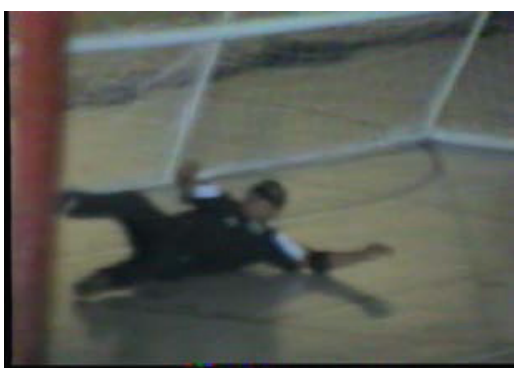

Figura 12 - Momento do gol

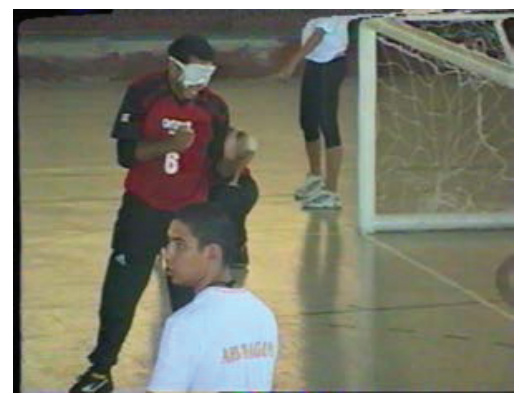

Figura 14 - Expressão de felicidade 